\title{
Felicidade Clandestina e Clandestina Felicidade
}

\author{
Avanúzia Ferreira Matias ${ }^{1}$
}

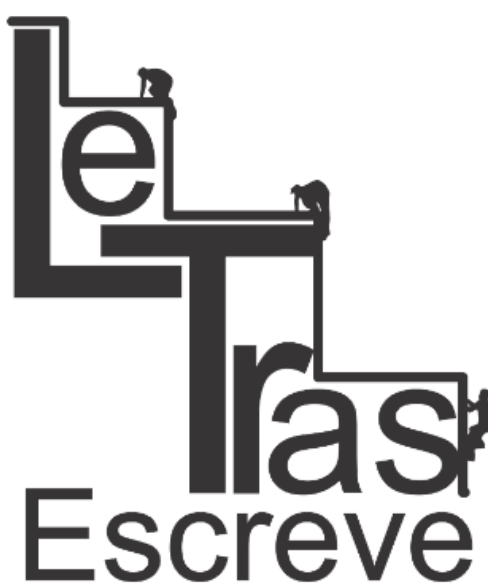

(ISSN 2238-8060)
Resumo: Este trabalho teve o propósito de apresentar Clarice Lispector, uma importante escritora do Modernismo Brasileiro, e um pouco de sua obra aos estudantes de uma turma de $3^{\circ}$ ano do ensino médio de uma escola da rede estadual de ensino do Ceará localizada em Fortaleza. Nosso objetivo foi, além de incentivar a leitura e a produção de texto, incitar os alunos para a interação com textos literários e reflexão sobre os fatos da ficção que dialogam com fatos reais. Fundamentamo-nos em Bakhtin (2002) para explorar o dialogismo, recurso responsável por revelar detalhes imprescindíveis em fatos vividos por muitas pessoas em momentos e movimentos distintos. Em termos metodológicos, o conteúdo foi apresentado aos alunos do $3^{\circ}$ ano do ensino médio em quatro etapas e, junto com o material didático de nossa autoria, também utilizamos o DVD Curta na Escola, que contém, dentre os oito vídeos, um curta-metragem que retrata partes da vida da autora aqui referida e cujo objetivo é realizar, em sala de aula, o uso de diferentes ferramentas para estimular os discentes a 1. descobrir o universo enigmático das narrativas de Clarice; 2. despertar o prazer pela leitura; 3. produzir textos a partir de uma releitura dos fatos narrados no livro e das experiências cotidianas. Nossos resultados foram satisfatórios, visto que a maioria dos alunos apreendeu o contexto socio-histórico e literário do assunto estudado, demonstrou interesse pela leitura das obras da autora e produziu textos coerentes sobre si mesmo, dialogando com o contexto literário escrito pela autora, o que, para nós, representou uma experiência exitosa.

Palavras-chave: literatura; Clarice Lispector; leitura; produção textual.

Sommario: Questo documento mira a presentare Clarice Lispector, importante scrittore di Modernismo brasiliano, e alcuni dei suoi lavori per gli studenti di una classe di $3^{\circ}$ anno in una scuola statale che si trova a Fortaleza, nel Ceará. II nostro obiettivo era, e incoraggiare la lettura e la produzione testuale, incoraggiare gli studenti per l'interazione con i testi letterari e di riflessione sui fatti dalla finzione che c'é il dialogo con i fatti reali. Ci basiamo nel Backtin (2002) per esplorare la dialogicità, responsabile delle risorse per rivelare dettagli importanti sui fatti vissuti da molte persone in diversi momenti e movimenti. Dal punto di vista metodologico, il contenuto è stato presentato agli studenti del $3^{\circ}$ anno di liceo in quattro fasi e, insieme con il materiale didattico costruito per noi, si usa anche il DVD Curta na Escola, che contiene, tra gli otto video, un cortometraggio raffiguranti parti della vita della l'autore citati nel presente documento e cui scopo è quello di eseguire in classe, l'utilizzo di diversi strumenti per incoraggiare gli studenti a 1. scoprire il mondo enigmatico di narrazioni della Clarice; 2 . risvegliare il piacere per la lettura; 3 . produrre testi di una reinterpretazione degli eventi nel libro e esperienze quotidiane. I nostri risultati sono stati soddisfacenti, poiché la maggior parte degli

${ }^{1}$ Professora de Língua Portuguesa (SEDUC-CE), Mestre em Linguística e Doutoranda em Educação (UFC). E-mail: avatias@bol.com.br

https://periodicos.unifap.br/index.php/letras

Macapá, v. 6, n. I, Io semestre, 2016. 
studenti ha sequestrato il contesto storico-sociale e letterario del soggetto studiato, hanno mostrato interesse per la lettura delle opere dell'autore e prodotti testi coerenti con se stessi, parlando con il contesto letterario scritto dall'autore, che, per noi, questa è stata un'esperienza di successo.

Parole chiave: letteratura; Clarice Lispector; lettura; produzione testuale.

\section{Introdução}

A obra de Clarice Lispector, ao mesmo tempo em que possui o poder de envolver, também possui o poder de encantar os leitores em um universo simultaneamente mítico, poético e linguístico, e o resultado dessa conjuntura é desmistificação do conceito que muitos alunos têm sobre leitura, de que essa é uma atividade "chata, cansativa, sem nenhum atrativo".

Desenvolver um trabalho com as obras de Clarice Lispector

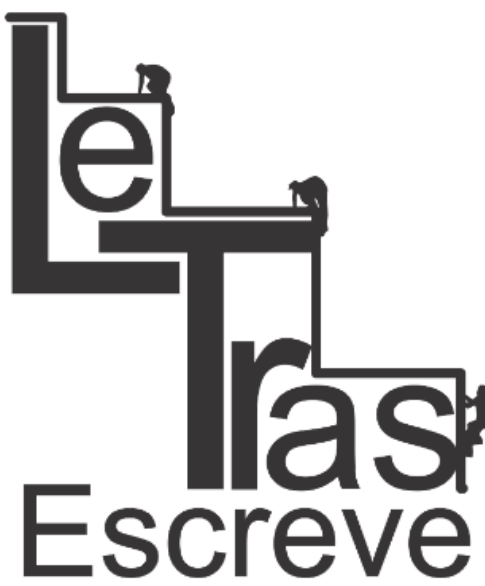

(ISSN 2238-8060) sempre nos oferece resultados inesperados, pois a autora, com sua forma atraente de cativar leitores, consegue envolvê-los em temáticas que vão desde questões existenciais até questões reais, como, por exemplo, discutir o papel da mulher na sociedade. É de grande relevância, em uma aula de literatura, poder levantar discussões sobre o papel do homem e da mulher na sociedade, e mais interessante ainda é fazer a intertextualidade com a obra de uma autora que, tendo morrido em 1977, continua tão atual, visto que suas temáticas abordam histórias extremamente contemporâneas, como situações de subordinação, de opressão, de exploração do sexo feminino pelo masculino, de hierarquia e relações de poder, de conflitos familiares e seus confrontos, bem como a consciência da própria individualidade.

A estreia oficial de Clarice Lispector no mundo literário se dá em 1943, com a publicação do romance Perto do Coração Selvagem, obra que mostra o caráter de inovação ficcional da autora, marcado, sobretudo, pela problemática existencial e estilo fragmentário.

Vinte e oito anos depois, no auge da carreira literária, Clarice publica Felicidade Clandestina, na qual a autora focaliza a análise da 


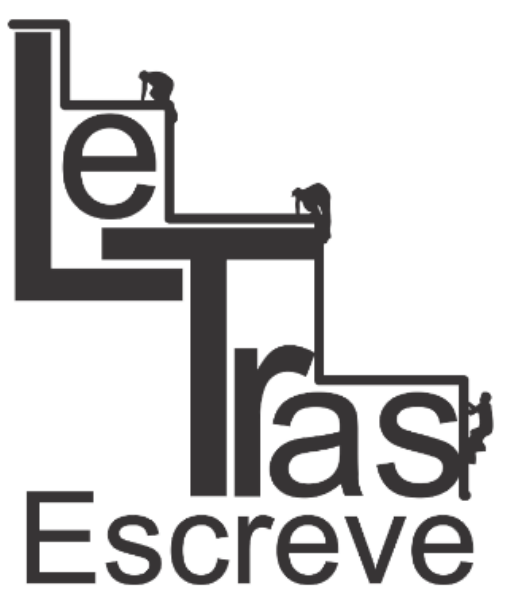

(ISSN 2238-8060) interioridade do ser humano. O livro reúne 25 textos de diferentes temas: infância, adolescência, família e amor. Uma das técnicas empregadas nesses textos é a narrativa em fluxo da consciência que se constitui em uma tentativa de representação dos processos mentais e interiores dos personagens.

Desse modo, através de um mergulho no mundo psicológico dos personagens, a autora traz à tona uma importante reflexão sobre as questões inerentes à existência humana e suas inquietações. Assim, os personagens comumente se apresentam ou como seres desconfiados, ou como indivíduos inadaptados ao contexto em que vivem ou como pessoas isoladas nas relações sociais. Tais personagens, na obra de Clarice, passam por um momento de epifania, que se relaciona a um momento de iluminação, ou seja, de uma tomada de consciência que o motiva a encarar o mundo em sua volta de outra maneira. Nessa perspectiva, epifania significa a descoberta da própria identidade a partir de um estímulo externo (como a menina que se torna "amante" do livro, em "Felicidade Clandestina"). Os personagens, nesse momento, descobrem a própria essência, aquilo que as distingue das demais e as transformam em indivíduos singulares.

\section{Características da obra de Clarice Lispector}

Em "Felicidade Clandestina", conto que dá nome ao livro de 1971, a narradora em $1^{a}$ pessoa conta a sua experiência de amor por um livro. A história se desencadeia em torno de uma "menina má" que oferece emprestado um livro à narradora, mas que sempre inventa alguma desculpa para não o entregar à colega. Até que, certa vez, a mãe da menina percebe o comportamento ruim da filha e entrega o livro à narradora, que passa a admirá-lo como se fosse um amante. O ponto central desse texto é o conceito de felicidade, por meio do qual a autora parece perguntar: "O que é a felicidade, afinal"?

https://periodicos.unifap.br/index.php/letras Macapá, v. 6, n. I, Io semestre, 2016. 


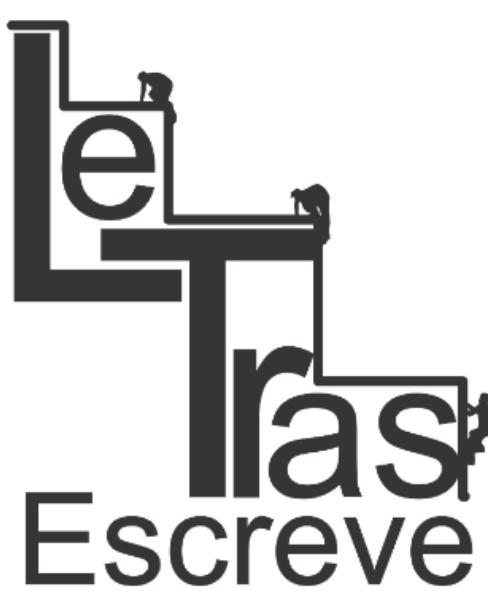

(ISSN 2238-8060)

No decorrer da história, a narradora de "Felicidade Clandestina" se utiliza de todas as estratégias possíveis para prolongar seu sentimento de felicidade representado pela posse do livro. A narradora, algumas vezes, chega a fingir esquecer que possui o livro, só para se redescobrir possuidora dele. É assim que sua felicidade aparece como um sentimento clandestino, uma vez que ela não pode se conscientizar de sua própria felicidade para que esse sentimento não se acabe.

Com base nas experiências narradas, podemos perceber que na obra de Clarice Lispector e, mais especificamente, nos contos de Felicidade Clandestina, estão presentes sentimentos e inquietações comuns a todo ser humano, o que permite um trabalho em sala de aula voltado para a realidade do jovem e seus próprios anseios e dúvidas em relação à vida, ao mundo e a si próprio.

Sobre a construção do estilo da autora, é importante ressaltar que Clarice é dona de um estilo especial de escrever, dessa forma conseguiu inserir-se no meio artístico-literário com um estilo questionador e reflexivo, com o qual convida o leitor a participar de uma relação dialógica. A respeito desta relação, Bakhtin (1992, p. 109) relata que o dialogismo nos permite enxergar uma verdade que não é evidenciada de forma clara, entre a tese e a antítese, ela "manifesta uma idêntica recusa tanto da tese como da antítese e constitui uma síntese dialética". De acordo com o autor, não há enunciação pura, o que há de fato é uma interação entre o que já foi enunciado e o que está sendo enunciado. Nessa perspectiva, não basta compreender uma enunciação, tampouco afirmar que ela é um ato subjetivo. É preciso compreender que qualquer enunciação mantém um diálogo com outras enunciações, de outros enunciadores. Dessa maneira, o discurso de Clarice em suas obras conduz o leitor a estabelecer uma relação entre a enunciação fictícia e a enunciação daquilo que de fato é resultado da interação social. O dialogismo é, portanto, o princípio constitutivo da linguagem da autora, que consegue, seguindo a lógica bakhtiniana, 


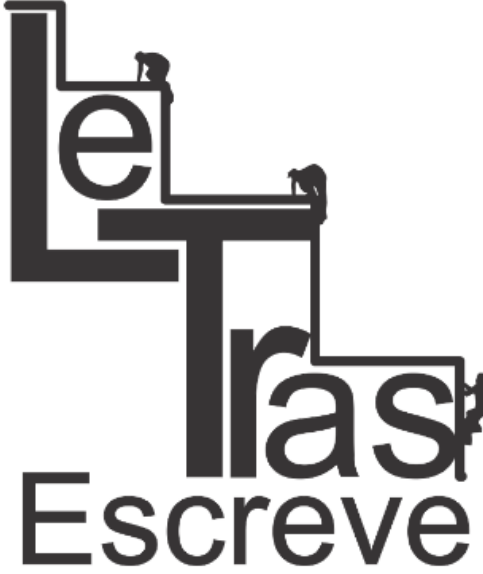

(ISSN 2238-8060)
Personificar-se na linguagem, tornar-se enunciados, converterse em posições de diferentes sujeitos expressas na linguagem para que entre eles possam surgir relações dialógicas. [...] As relações dialógicas são absolutamente impossíveis sem relações lógicas e concreto-semânticas, mas são irredutíveis a estas e têm especificidade própria. Para se tornarem dialógicas, as relações lógicas e concreto-semânticas devem, como já dissemos, materializar-se, ou seja, devem passar a outro campo da existência, devem tornar-se discurso, ou seja, enunciado, e ganhar autor, criador de dado enunciado cuja posição ela expressa (BAKHTIN, 2002, p. 184).

Todavia, é necessário examinar o dialogismo discursivo considerando-se dois aspectos: o da interação verbal (entre o enunciador e o enunciatário do texto) e o da intertextualidade no interior do discurso.

Segundo Barros (1994, p. 2-4), "o dialogismo decorre da interação verbal que se estabelece entre enunciador e enunciatário no espaço do texto". Nesse aspecto, o termo representa a interação entre o "eu" e o "tu" no texto, donde as constantes referências ao papel do "outro" durante a construção do sentido afirmam que nenhuma palavra é nossa, porquanto traz em si a perspectiva de outra voz. O dialogismo de Clarice pode ser considerado também como o "diálogo entre os vários textos da cultura, que se instala no interior de cada texto e o define".

O estilo literário de Clarice Lispector é, indiscutivelmente, dialógico, pois com o uso do seu poder de manipulação linguística, usado a favor da elaboração de seus textos, consegue estabelecer relações dialógicas em seu discurso e estabelecer uma condição para que se possa constituir o sentido com a ajuda e participação do leitor. Ela consegue persuadi-lo para que este, em suas interpretações enquanto lê a obra, faça relações com a realidade e, nestas relações, construídas com a incitação do texto, reflita sobre valores, questione a atitude humana diante dos fatos e tome consciência de que na vida sempre estamos fazendo escolhas, elegendo prioridades, alimentando vaidades, mudando de opinião, de comportamento, estamos sempre à procura de mais e mais.

https://periodicos.unifap.br/index.php/letras Macapá, v. 6, n. I, Io semestre, 2016. 
Nesse contexto, o querer é infinito, pois, inesgotavelmente, sempre há coisas que queremos, outras que deixamos de querer e outras que talvez nunca alcançaremos, já que o ser humano nunca está totalmente satisfeito em relação à sua existência.

\section{Objetivos do uso do filme}

Objetivamos, com o uso do curta-metragem, apresentar características da obra da escritora Clarice Lispector, despertando, através dessa mídia, o interesse pela leitura, numa tentativa de mostrar que, assim como na ficção, a realidade também é composta de aventuras que fogem à normalidade e que cruzam com outras histórias para quebrar a rotina, às vezes levando-nos a fazer coisas

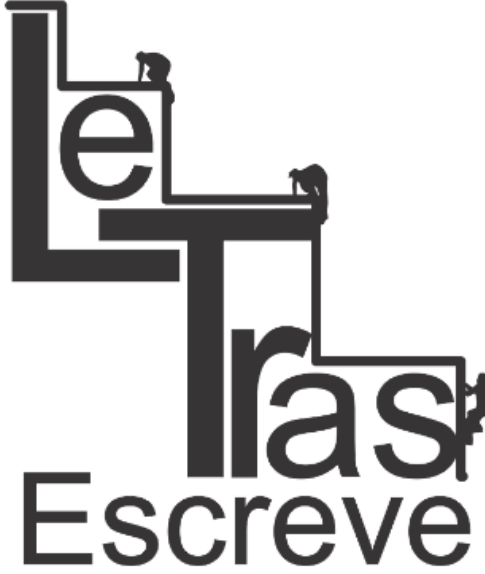

(ISSN 2238-8060) surpreendentes e prazerosas. Também tínhamos a intenção de estimular nos alunos o prazer pela escrita, pois esta pode ser uma atividade divertida e através da qual podemos descobrir mundos além da nossa realidade - mundos com os quais sonhamos ou que planejamos para nós.

\section{Metodologia}

Nosso trabalho desenvolveu-se em quatro etapas:

10 passo: a professora de Literatura, em duas aulas, apresentou a biografia de Clarice Lispector, falou sobre as características literárias da $3^{a}$ Geração Modernista Brasileira, sobre o estilo literário da escritora, sobre sua obra, destacando ainda os seguintes aspectos: sua infância em Recife, sua paixão pela obra de Monteiro Lobato, sua ida para o Rio de Janeiro, sua vivência no exterior, o acidente com o cigarro e sua solidão.

2o passo: os alunos assistiram ao filme Clandestina Felicidade e, em seguida, conversaram, apoiados pela mediação da professora, sobre as várias histórias de Clarice que existem neste vídeo, levantando questões sobre o que a junção destas histórias 


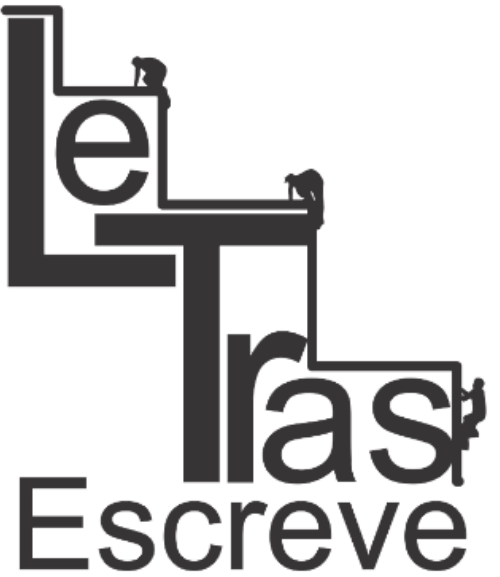

(ISSN 2238-8060) nos faz perceber, sobre a capacidade que a autora tem de ver o mundo com olhos que enxergam além do que se pode ver, sobre o poder da imaginação, que transforma o viver da menina em um ato livre e capaz de fazer tudo acontecer.

3o passo: os alunos, esclarecidos das histórias contextualizadas no curta, escolheram uma delas e lhes foi proposto escrever um texto em que suas histórias cruzassem com uma das histórias da infância de Clarice. O resultado foram textos criativos e com outros significados para a felicidade.

4o passo: os alunos, mais esclarecidos sobre as características da obra de Clarice Lispector, foram ao Multimeios da escola, escolheram uma obra da autora, leram e, em seguida, apresentaram suas impressões em uma avaliação na qual foram analisados os seguintes aspectos:

- características da $3^{a}$ Geração Modernista Brasileira;

- vida e obra de Clarice Lispector;

- intertextualidade entre o assunto tratado nas obras e os acontecimentos reais de nossas vidas;

- coerência e coesão textual;

- adequação às regras gramaticais.

\section{Resultados}

Os textos produzidos pelos alunos na $3^{a}$ fase da oficina revelaram muitos significados para a proposta apresentada. Os relatos feitos por eles revelam uma profunda carência de atenção. Em seus textos, é perceptível que o homem moderno apresenta uma grande necessidade de ter alguém com quem conversar sobre suas ânsias e angústias, sentimentos pelos quais todo ser humano está predisposto a passar, pois são consequências naturais da existência.

$\mathrm{Na} 4^{\mathrm{a}}$ fase, os alunos perceberam, ao ler a ficção de Clarice Lispector, que a leitura não precisa ser uma prática cansativa e

https://periodicos.unifap.br/index.php/letras Macapá, v. 6, n. I, Io semestre, 2016. 


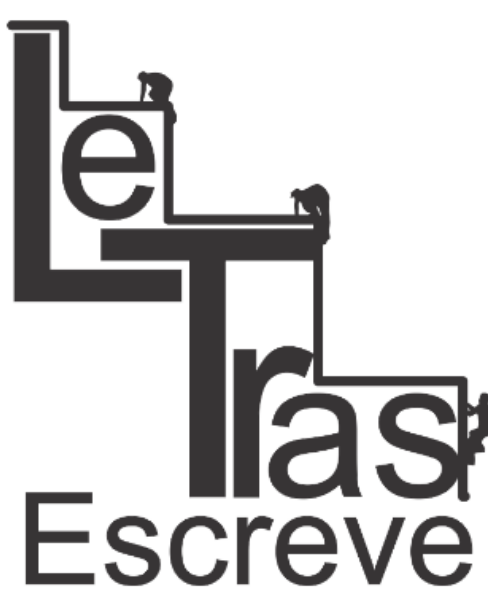

(ISSN 2238-8060) enfadonha. Em nossos resultados, pudemos comprovar que, para esses alunos, a leitura revelou-se como uma atividade prazerosa na qual existem pessoas incompletas, insatisfeitas e que estão sempre à procura de algo, como qualquer ser humano, sem esperar respostas para tudo e sem ter que seguir um único padrão de vida, preocupando-se apenas em encontrar a felicidade.

Consideramos a atividade bastante proveitosa, pois os alunos aceitaram-na muito bem e foram participativos no desenvolvimento da proposta de ler e escrever textos a partir da exposição sobre a vida e a obra de Clarice Lispector. Nosso objetivo de despertar o interesse pela leitura foi alcançado, pois os alunos interessaram-se por conhecer suas obras, procuram por romances e contos na biblioteca, realizaram leituras e comprovaram, em avaliação, um aprendizado significativo, considerando o contexto social, econômico e cultural no qual estão inseridos. Como a obra da escritora conduz os personagens por caminhos incertos e misteriosos, algo que interessa e fascina os adolescentes, eles conseguiram enxergar nas histórias ações de pessoas incompletas e que estão sempre à procura de algo, como qualquer ser humano, sem esperar respostas para tudo e sem ter que seguir um padrão de vida, preocupando-se apenas em encontrar a Felicidade.

\section{Conclusão}

Chegamos à conclusão de que a aula de leitura e de produção textual pode ser mais bem aceita se contextualizarmos essa prática dentro de um universo que dialogue com práticas as quais os alunos vivenciam em sua individualidade. É necessário, para tanto, capacitar o educando para as mais diversas práticas sociais de leitura e escrita, corroborando, assim, para a aquisição do multiletramento, atrelado às exigências do mundo moderno, que exige, além do letramento em diversos gêneros textuais (sejam eles literários ou não), o letramento crítico.

https://periodicos.unifap.br/index.php/letras Macapá, v. 6, n. I, Io semestre, 2016. 
Concordamos com Xavier (2005) ao afirmar que em plena era da informação, a escola como agenciadora de conhecimento precisa cumprir seu papel de letrar essa geração que nasce e cresce vivenciando os avanços das tecnologias da informação e comunicação.

\section{Referências bibliográficas}

ABAURRE, M. L.; PONTARA, M. N. Literatura Brasileira: tempos, leitores e leituras. São Paulo: Moderna, 2005.

BAKHTIN, M. Problemas na poética de Dostoiéviski. (Trad.) Paulo Bezerra. Rio de Janeiro: Florense Universitária, 2002.

. Estética da criação verbal. (Trad.) Maria Ermantina Galvão

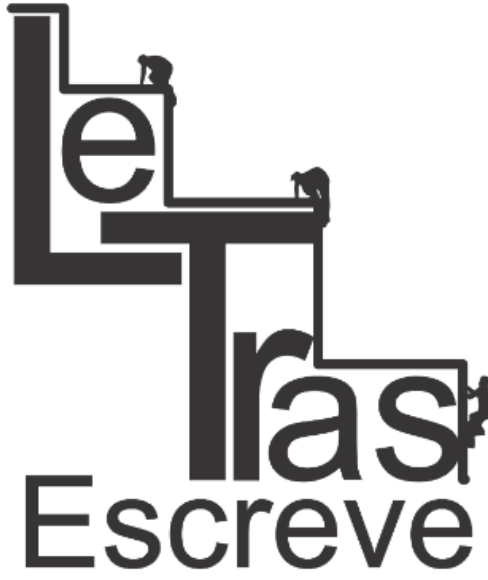

(ISSN 2238-8060)
Gomes. São Paulo: Martins Fontes, 1997.

. Marxismo e filosofia da linguagem. (Trad.) Michel Lahud e Yara Frateschi. São Paulo: Hucutec, 1992.

BARROS, D. P. de. Dialogismo, Polifonia e Enunciação. In BARROS, D. P. de. e FIORIN, J. L. (orgs.). Dialogismo, polifonia e intertextualidade: Em torno de Bakhtin. São Paulo: Edusp, 1994.

Coleção Curta na Escola: Clandestina Felicidade, disponível em http://portacurtas.org.br/curtanaescola/pop 160.asp?Cod=311\&exib= $\underline{5513}$

LISPECTOR, C. Felicidade Clandestina. Rio de Janeiro: Rocco, 1998.

XAVIER, Antonio Carlos. Letramento digital e ensino. In. SANTOS, Carmi Ferraz \& MENDONÇA, Márcia (orgs). Alfabetização e letramento: conceitos e relações. Belo Horizonte: Autêntica, 2005, pp. 133-148.

Recebido em 10/04/2016. Aprovado em 20/05/2016. 